\title{
RELATO DE CASO Considerações sobre a clínica e o tratamento de uma manifestação incomum do transtorno dismórfico corporal: a síndrome de referência olfatória
}

\author{
Considerations on the clinical picture and treatment \\ of an unusual manifestation of body dysmorphic \\ disorder: the olfactory reference syndrome \\ Cristiane Maluhy Gebara', Tito Paes de Barros Neto ${ }^{1}$
}

\section{RESUMO}

Neste relato, descreve-se o caso de um rapaz de 23 anos que apresentava a crença de exalar um odor desagradável proveniente da transpiração e acreditava que incomodava as outras pessoas. O paciente foi medicado com amissulprida associada a técnicas de terapia cognitivo-comportamental (TCC), tendo havido acentuada melhora do quadro clínico. Foram abor-

\section{Palavras-chave}

Exposição, síndrome de referência olfatória, terapia cognitivo-comportamental, transtornos somatoformes.

\section{Keywords}

Exposure, olfactory reference syndrome, cognitive behavior therapy, somatoform disorders. dados aspectos relativos à nosologia e às manifestações clínicas da síndrome de referência olfatória (SRO), e o seu tratamento foi discutido. Observou-se que experimentos comportamentais envolvendo exposição com desafio às crenças delirantes podem ser úteis no tratamento desse transtorno e que os antipsicóticos, particularmente a amissulprida, podem ser uma boa alternativa aos inibidores de recaptação da serotonina (IRSs) no tratamento da SRO.

\begin{abstract}
We report the case of a 23 year old man who believed he emitted an unpleasant odor from perspiration which he's believed bothered other people. He was treated with amisulpride in combination with cognitive-behavioral therapy (CBT), and there was marked improvement in the clinical status. Aspects related to the clinical manifestations and nosology of olfactory reference syndrome (ORS) and treatment were discussed. It was noted that behavioral experiments involving exposure with challenge to the delusional beliefs may be useful in the treatment of this disorder, and antipsychotics, particularly amisulpride may be a good alternative to the serotonin reuptake inhibitors (SRIS) in the treatment of ORS.
\end{abstract}

1 Universidade de São Paulo (USP), Hospital das Clínicas, Instituto de Psiquiatria, Departamento de Psiquiatria, Programa de Ansiedade (AMBAN). 


\section{INTRODUÇÃO}

A síndrome de referência olfatória (SRO) foi descrita há mais de um século' e se caracteriza pela preocupação com uma crença falsa de emitir um odor desagradável ou mesmo ofensivo, que não é percebido pelos outros. Poucos estudos foram realizados até o momento abordando esse tema. Pryse-Phillips ${ }^{2}$ introduziu o termo síndrome de referência olfatória para diferenciá-la dos sintomas olfatórios presentes na esquizofrenia, na depressão e na epilepsia do lobo temporal. O transtorno é grave e o sofrimento é intenso, podendo levar à incapacitação. O DSM-IV³, apesar de não classificar a SRO em uma categoria diagnóstica específica, a considera um transtorno delirante de tipo somático. Em um recente artigo de revisão sistemática, em que foram encontrados 84 relatos de casos de $\mathrm{SRO}$, os autores desses relatos expressaram ceticismo quanto à natureza delirante da crença em boa parte dos casos ${ }^{4}$. Outro estudo, realizado no Brasil por Prazeres et al. ${ }^{5}$, observou que apenas $21 \%$ dos pacientes apresentavam crenças delirantes. No entanto, um estudo mais recente observou que as crenças em relação ao odor corporal eram delirantes em 85\% dos casos $^{6}$.

Para alguns autores, a SRO estaria dentro do espectro da ansiedade social, incluindo-se a fobia social, Taijin Kyofusho e transtorno dismórfico corporal (TDC) ${ }^{7}$. Há ainda autores que acreditam que a SRO faça parte do espectro obsessivo-compulsivo ${ }^{8}$.

Para Begum e McKenna ${ }^{4}$, a SRO é um transtorno psiquiátrico primário que não se encaixa na classificação do DSM-IV como um subtipo de transtorno delirante. Feusner et al. ${ }^{9}$, a exemplo de Lochner e Stein ${ }^{7}$, propuseram a inclusão de critérios específicos para o diagnóstico da SRO e recomendaram que esta venha a fazer parte do apêndice do DSM-V. Prazeres et al. ${ }^{5}$ entendem que a SRO seja um subtipo de transtorno dismórfico corporal.

O fato é que o status nosológico da SRO é uma questão controversa e ainda existem dúvidas sobre quais tratamentos são eficazes. Os estudos em que os pacientes foram submetidos à psicoterapia são escassos.

Em relação ao tratamento, as drogas mais utilizadas são os antidepressivos, sobretudo os inibidores de recaptação da serotonina (IRSs) ${ }^{9}$, embora os antipsicóticos também sejam citados ${ }^{4}$. Há relatos de casos que sugerem que a combinação de ambos seja eficaz ${ }^{5}$. Note-se que as crenças presentes nos casos de SRO frequentemente são delirantes. A terapia comportamental também aparece como uma boa alternativa de tratamento ${ }^{4}$. Ao se fazer um levantamento sobre esses aspectos, pode-se afirmar que os estudos que abordam o tratamento da SRO são bastante limitados ${ }^{6}$.

O objetivo deste relato de caso é propor que um antipsicótico associado à terapia cognitivo-comportamental possa ser eficaz no tratamento da SRO.

\section{DESCRIÇÃO DO CASO}

O paciente, um homem de 23 anos, chegou ao consultório e relatou com dificuldade o problema: acreditava exalar um odor desagradável pela transpiração e que isso incomodava as pessoas. Ele afirmava saber disso, pois notava que as pessoas se afastavam dele. O paciente terminou com dificuldade o ensino médio, mas, por causa de sua forte convicção de que exalava um odor desagradável, desistiu de estudar, abandonando os planos de ingressar na faculdade, evitando até sair de casa. Permanecia o dia todo no computador, principalmente na internet. Esse paciente encontrava-se confinado à sua casa havia seis anos.

Relatou que aos 16 anos, quando voltava da escola, num dia quente, sua mãe pediu para que tomasse banho. A partir desse fato, passou a se preocupar com o suor e o odor que exalava, embora negasse sudorese excessiva. Chegava a tomar quatro banhos por dia. Procurou vários dermatologistas e experimentou diversas marcas de desodorantes para tentar resolver o problema. Foi atendido por um terapeuta de orientação psicodinâmica durante cinco anos.

Ele relatou ter um bom relacionamento com os pais e o irmão mais velho. Disse ter sido uma criança muito ativa. Jogava futebol, tinha vários amigos, mas preferia conversar com adultos.

O paciente apresentava diversas cognições: "pareço não pertencer a nenhum grupo", "me sinto com cem anos, sou velho para várias coisas", "nunca mais vou alcançar meus colegas", tudo está no lugar errado, tudo é uma escuridão".

Ao exame psíquico, apresentava esquiva de contato interpessoal, ideias delirantes, autorreferência e autoestima diminuída.

Foi feita a hipótese diagnóstica de SRO. O paciente foi medicado com paroxetina, mas teve muitos efeitos colaterais e nenhum ganho terapêutico. Seu grau de convicção em relação a exalar o odor desagradável chegava a 95\%. Foi suspensa a paroxetina e introduzida a sertralina até $100 \mathrm{mg}$ ao dia, sem que houvesse qualquer melhora do quadro, com diversos efeitos colaterais, como insônia, inquietação e tremor. Foi então, associada a risperidona, $1 \mathrm{mg}$ ao dia, mas o paciente parou a medicação por conta própria, alegando sonolência excessiva e sentimentos de estranheza. Foi introduzida a amissulprida na dose de $50 \mathrm{mg}$ ao dia e foi encaminhado para terapia cognitivo-comportamental. O paciente referiu alguma melhora com a nova medicação. Sentiu-se mais tranquilo, mas mantinha a convicção de exalar o odor desagradável.

$\mathrm{Na}$ abordagem cognitivo-comportamental, foram feitas algumas sessões de exposição ao vivo, que caracterizavam experimentos comportamentais, e de reestruturação cognitiva. A primeira sessão de exposição foi feita na rua e consistia em, após o paciente fazer uso de uma marca de desodorante, cujo rótulo foi coberto, perguntar para os transeuntes se percebiam algum odor desagradável no paciente. A ideia era configurar uma pretensa pesquisa para uma marca de deso- 
dorante que não poderia ser identificada. Mais de 20 pessoas responderam às perguntas e não houve nenhuma resposta de que o odor que o paciente exalava era desagradável. A convicção de que exalava tal odor passou de 95\% para 75\%. As suas cognições passaram a ser mais funcionais. ("agora penso em fazer algo", "quero estar com pessoas"). A dose de amissulprida foi ajustada para $100 \mathrm{mg}$ ao dia, com o paciente estando mais ativo; ele fez uma trilha e viajou para a praia.

O paciente prosseguiu com suas sessões de exposição. A terapeuta sugeriu um lugar público fechado. O elevador de um shopping center foi escolhido para esse outro experimento comportamental. No elevador, a terapeuta perguntava às pessoas se sentiam algum odor estranho. Foram feitas diversas viagens de elevador e só uma pessoa respondeu que percebia um odor diferente, mas não desagradável. Sua convicção em relação a exalar o odor passou para 50\%.

Atualmente, o paciente encontra-se matriculado em um curso pré-vestibular. Ele tem saído com os amigos, o que não fazia antes, e fez um trabalho em um blog para um familiar. Em relação ao odor corporal, o paciente diz que este não incomoda todas as pessoas. Relata tomar um ou dois banhos por dia. Nas aulas, escolhe uma cadeira em que fique perto das pessoas que já conhece, mas ainda evita pegar elevador lotado.

Após algumas sessões de reestruturação cognitiva, sua convicção em relação a exalar o odor desagradável caiu para 25\%.

\section{DISCUSSÃO}

Um comentário sobre o diagnóstico da SRO nos parece oportuno, uma vez que em alguns artigos ela aparece dentro dos espectros da ansiedade social ${ }^{7}$ e do transtorno obsessivo-compulsivo $(T O C)^{8}$ e guarda semelhanças com o TDC. Sobre essa questão, é importante lembrar que a esquiva e o medo de situações sociais que ocorre na SRO são secundários à crença de exalar o odor. O mesmo se pode dizer em relação ao TOC, por exemplo, em rituais de lavagem na tentativa de eliminar o odor. Em relação ao TDC, há uma preocupação em relação a um defeito imaginário. E, neste caso, pode-se especular se uma crença a respeito de um funcionamento defectivo do corpo estaria se manifestando.

Técnicas específicas de TCC podem ser úteis no tratamento de sintomas psicóticos positivos como alucinações e delírios, sobretudo quando causam sofrimento ${ }^{10}$. No caso desse paciente, a exposição com o desafio à crença, associada à amissulprida, levou à melhora do quadro. Vale ressaltar que apenas um artigo foi localizado, em que a amissulprida foi usada no tratamento da SRO: um relato de caso ${ }^{11}$. Segundo Phillips e Menard ${ }^{6}$, os IRSs são as drogas de primeira escoIha, associados ou não a antipsicóticos. Estes últimos, usados isoladamente, também podem ser uma boa alternativa. No caso do paciente em questão, não foi isso que ocorreu. Ele não respondeu a IRSs, mas a sua resposta ao antipsicótico foi bastante favorável, contrariando o que existe na literatu- ra e denotando que antipsicóticos, particularmente a amissulprida, são uma boa alternativa no tratamento da SRO. No entanto, é importante realçar que este artigo é um relato de caso, o que dificulta a generalização do resultado.

O uso de experimentos comportamentais que desafiam os delírios é encontrado na literatura e leva à redução da convicção nas crenças $^{10,12}$. Isso pode ser observado no paciente, que, após ter se submetido às sessões de TCC, estimou ter havido uma redução de $75 \%$ na sua convicção de exalar o odor. Remanesce a questão de as crenças da SRO serem ou não delirantes. Poderiam ser ideias deliroides? Ou mesmo prevalentes? Essa é uma questão controversa que parece estar longe de se resolver. A esse respeito, Feusner et al. ${ }^{9}$, em sua sugestão de haver critérios específicos para o diagnóstico da SRO no DSM-V, propõem discriminar se as crenças são: 1) provavelmente não verdadeiras, 2) provavelmente verdadeiras ou 3) indubitavelmente verdadeiras. Desse ponto de vista, pode-se fazer um paralelo entre essa especificação e a questão de serem ideias prevalentes, deliroides ou delirantes.

Em relação às cognições relatadas pelo paciente, também houve progresso, com o abandono parcial do discurso repetitivo em relação aos anos que ficou sem fazer nada, voltando-se para o presente e também para o futuro próximo.

São necessários mais estudos controlados que evidenciem quais são os tratamentos mais eficazes da SRO.

\section{REFERÊNCIAS}

1. Potts CS. Two cases of hallucination of smell. University of Pennsylvania Medical Magazine. 1891:226.

2. Pryse-Phillips W. An olfactory reference syndrome. Acta Psychiatr Scand. 1971;47:484-509.

3. American Psychiatric Association. Diagnostic and Statistical Manual of Mental Disorders Fourth Edition (DSM-IV). Washington, DC; 2000.

4. Begum M, McKenna PJ. Olfactory reference syndrome: systematic review of the world literature. Psychol Med. 2011;41:453-61.

5. Prazeres AM, Fontenelle LF, Mendlowicz MV, De Mathis MA, Ferrão YA, de Brito NF, et al. Olfactory reference syndrome as a subtype of body dismorphic disorder. J Clin Psychiatry. 2010;71:87-9.

6. Phillips KA, Menard W. Olfactory reference syndrome: demographic and clinical features of imagined body. Gen Hosp Psychiatry. 2011;33:398-406.

7. Lochner C, Stein DG. Olfactory reference syndrome: diagnostic criteria and a differential diagnosis. J Postgrad Med. 2003;24:328-31.

8. Stein DJ, Le Roux L, Bouwer C, Van Heerden B. Is olfactory reference syndrome an obsessive-compulsive spectrum disorder? - two cases and a discussion. J Neuropsychiatry Clin Neurosci. 1998;10:96-9.

9. Feusner JD, Phillips KA, Stein DJ. Olfactory reference syndrome: issues for DSM-V. Depress Anxiety. 2010;27:592-9.

10. Kuipers E, Garrety P, Fowler D, Dunn G, Bebbington P, Freeman D, et al. London- East Anglia randomised controlled trial of cognitive-behavioural therapy for psychosis I: effects of the treatment phase. Br J Psychiatry. 1997;171:319-27.

11. Yeh YW, Chen CK, Huang SY, Kuo SC, Chen CY, Chen CL. Successful treatment with amisulpride for the progression of olfactory reference syndrome to schizophrenia. Progr Neuropsychopharmacol Biol Psychiatry. 2009;33:579-80.

12. Chadwick P, Birchwood M, Trower P. Cognitive therapy for delusion, voices and paranoia. Chichester: John Wiley \& Sons; 1998. p. 69-90. 